\title{
A Comparative Study of Inhaled Nitric Oxide and an Intravenously Administered Nitric Oxide Donor in Acute Pulmonary Hypertension
}

This article was published in the following Dove Press journal: Drug Design, Development and Therapy

\author{
Anna Stene Hurtsén (D) ${ }^{1,2}$ \\ Ilya Zorikhin Nilsson' \\ Emanuel M Dogan' \\ Kristofer F Nilsson (iD) \\ 'Department of Cardiothoracic and \\ Vascular Surgery, Faculty of Medicine and \\ Health, Örebro University, Örebro, \\ Sweden; ${ }^{2}$ Centre for Clinical Research \\ and Education, Karlstad Central Hospital, \\ Karlstad, Sweden
}

\begin{abstract}
Purpose: Inhaled nitric oxide (iNO) selectively vasodilates the pulmonary circulation but the effects are sometimes insufficient. Available intravenous (iv) substances are non-selective and cause systemic side effects. The pulmonary and systemic effects of iNO and an iv mono-organic nitrite (PDNO) were compared in porcine models of acute pulmonary hypertension.
\end{abstract}

Methods: In anesthetized piglets, dose-response experiments of iv PDNO at normal pulmonary arterial pressure $(n=10)$ were executed. Dose-response experiments of iv PDNO $(n=6)$ and iNO $(n=7)$ were performed during pharmacologically induced pulmonary hypertension (U46619 iv). The effects of iv PDNO and iNO were also explored in 5 mins of hypoxia-induced increase in pulmonary pressure $(\mathrm{n}=2-4)$.

Results: PDNO (15, 30, 45 and $60 \mathrm{nmol} \mathrm{NO} \mathrm{kg}{ }^{-1} \mathrm{~min}^{-1}$ iv) and $\mathrm{iNO}(5,10,20$ and $40 \mathrm{ppm}$ which corresponded to $56,112,227,449 \mathrm{nmol} \mathrm{NO} \mathrm{kg}{ }^{-1} \mathrm{~min}^{-1}$, respectively) significantly decreased the U46619-increased mean pulmonary arterial pressure (MPAP) and pulmonary vascular resistance (PVR) to a similar degree without significant decreases in mean arterial pressure (MAP) or systemic vascular resistance (SVR). iNO caused increased levels of methemoglobin. At an equivalent delivered NO quantity (iNO $5 \mathrm{ppm}$ and PDNO $45 \mathrm{nmol} \mathrm{kg}^{-1} \min ^{-1}$ iv), PDNO decreased PVR and SVR significantly more than iNO. Both drugs counteracted hypoxia-induced pulmonary vasoconstriction and they decreased the ratio of PVR and SVR in both settings.

Conclusion: Intravenous PDNO was a more potent pulmonary vasodilator than iNO in pulmonary hypertension, with no severe side effects. Hence, this study supports the potential of iv PDNO in the treatment of acute pulmonary hypertension.

Keywords: PDNO, inhaled NO, acute pulmonary hypertension, hypoxia-induced vasoconstriction, U46619

\section{Introduction}

Pulmonary hypertension is traditionally defined as a mean pressure in the pulmonary artery over $25 \mathrm{~mm} \mathrm{Hg}$ at rest. ${ }^{1}$ An acute increase in the pulmonary arterial pressure is common in intensive care patients and correlates to increased mortality, partly due to the absence of an efficient pharmacologic approach. ${ }^{2,3}$ The pulmonary circulation is a low pressure-high flow system and can tolerate a severalfold increase in cardiac output under normal conditions. ${ }^{4}$ When pulmonary vessels constrict due to conditions such as acute respiratory failure and sepsis, or become mechanically obstructed (ie, pulmonary embolism), the pulmonary pressure rises, ${ }^{5-7}$ increasing afterload of the right ventricle. Since the right ventricle is afterload intolerant, ${ }^{8}$ a hemodynamic malfunction manifests, eventually leading to circulatory collapse. ${ }^{9}$
Correspondence: Kristofer F Nilsson Department of Cardiothoracic and Vascular Surgery, Örebro University Hospital, Örebro SE-70I 85, Sweden

Tel +46 196020352

Email Kristofer-bo-ingemar. nilsson@regionorebrolan.se 
Nitric oxide (NO) is an endogenous signal substance and vasodilator, ${ }^{10,11}$ simple in structure but complex in chemistry. Due to the reactivity of free NO in tissue, the synthesis has to be rapid when requested, and it is metabolized and cleared quickly. ${ }^{12}$ Inhalation of NO (iNO) is of particular interest in pulmonary hypertension considering its selective pulmonary action ${ }^{13-16}$ and distribution to ventilated lung segments. ${ }^{17}$ However, the summarized effect of iNO remains controversial since improved survival rates have not been shown in adult intensive care patients. ${ }^{18}$ Today, iNO may be considered as pharmacological therapy in hypoxemic infants, ${ }^{19}$ but not on a routine basis in any category of acute respiratory distress syndrome (ARDS). ${ }^{18,20,21}$ Nonetheless, iNO is used in adult ARDS as a "rescue agent" worldwide since it improves arterial oxygenation. ${ }^{20,22}$ The enhancement of arterial oxygenation is however temporary (up to $24 \mathrm{hrs}$ ) and potential toxicity is of concern. ${ }^{18}$ Firstly, in high concentrations, iNO reacts with superoxide anions forming potent oxidants that damage tissues through lipid peroxidation, ${ }^{23}$ and the risk of renal injury is not negligible. ${ }^{24}$ Secondly, methemoglobin is produced, impairing oxygen transportation. ${ }^{25}$

Moreover, iNO is, in some conditions, insufficient and additional vasodilation may be required. It is suggested that iNO acts in small vessels peripherally in the pulmonary arterial tree. An additional effect in larger pulmonary vessels could possibly be generated by an intravenous (iv) substance ${ }^{26}$ Free NO is, however, difficult to handle for therapeutic use, except in inhaled form, due to rapid inactivation when encountering hemoglobin and the formation of nitric dioxide in reaction with oxygen. ${ }^{11,27}$ Different molecular carriers may be utilized to stabilize the radical in a solution until time of release. Numerous substances have been developed but few are clinically available. ${ }^{28}$ Two types of NO donor drugs have reached the market, organic nitrates and sodium nitroprusside, but none are indicated for acute pulmonary hypertension due to adverse side effects. ${ }^{28,29}$ Nitroprusside is sensitive to photolysis and has been reported to cause cyanide intoxication after long-term use. ${ }^{28,30}$ Organic nitrates show rapid tolerance development and cause distinct systemic hypotension. ${ }^{31}$ Organic nitrites have also been studied, but little progress has been made in examining these substances in human clinical trials. ${ }^{32}$ These do not present tolerance development in animal studies and are, therefore, perhaps clinically advantageous compared to organic nitrates. ${ }^{33-35}$ However, the problem with systemic hypotension remains and formation of methemoglobin have been reported. ${ }^{36-38}$
Thus, new alternatives to NO donor drugs are needed. ${ }^{28}$ The recently synthesized 1,2-propanediol mono-organic nitrites (PDNO) exhibit some selectivity towards the pulmonary circulation ${ }^{34,35,39}$ and are of clinical interest for further investigation concerning pulmonary potency and systemic side effects in the context of acute pulmonary hypertension, but a direct comparison with the gold standard pulmonary vasodilator, iNO, has not been done. Therefore, in the present study, we have investigated and compared the pulmonary and systemic effects of iNO and PDNO in porcine models of acute pulmonary hypertension induced by a pulmonary vasoconstrictor and by hypoxia.

\section{Materials and Methods Study Group}

An interventional exploratory animal study was conducted in the research laboratory at Örebro University Hospital, September $4-15,2017$. The study comprised 16 locally farmed, 3-4 month old domestic Hampshire and Yorkshire crossbreed pigs weighing $21-34 \mathrm{~kg}$. The study was approved by the regional animal ethics committee in Linköping, Sweden (ID: 953), controlled by a licensed veterinarian and performed by an experienced diploma-certified animal research team in compliance with European conventions of experimental animal protection. ${ }^{40}$

\section{Animal Preparation and Monitoring}

The animals were brought to the laboratory in the morning of each trial day, having been sedated by injection of 6-7 mL $40 \mathrm{mg} \mathrm{mL}^{-1}$ azaperone (Stresnil Elanco, Herlev, Denmark) intramuscularly (IM) before the 30-min transportation. In the laboratory, anesthesia was induced by an IM injection of $6 \mathrm{mg} \mathrm{kg}^{-1}$ of zolazepam and tiletamine (Zoletile Forte, Virbac, Kolding, Denmark) and $4 \mathrm{mg} \mathrm{kg}^{-1}$ azaperone. Atropine (Mylan, Stockholm, Sweden) $1.5 \mathrm{mg}$ was administered IM and a single dose of cefuroxime $750 \mathrm{mg}$ (GlaxoSmithKline SK AB, Solna, Sweden) was given in a peripheral vein catheter $\left(1.1 \mathrm{~mm}\right.$, Venflon ${ }^{\mathrm{TM}}$ Pro Safety, BD, Helsingborg, Sweden). After orotracheal intubation with a $6 \mathrm{~mm}$ endotracheal tube (Covidien, Tullamore, Ireland), the animals were connected to a ventilator (PV 501, Breas Medical AB, Sweden) and to continuous infusions of propofol 5-15 mg kg-1 $\mathrm{h}^{-1}$ (Fresenius Kabi, Uppsala, Sweden), fentanyl 5-20 $\mu \mathrm{g} \mathrm{kg}^{-1} \mathrm{~h}^{-1}$ (Meda, Solna, Sweden), $5 \%$ glucose $0.5 \mathrm{~mL} \mathrm{~kg}^{-1} \mathrm{~h}^{-1}$ (Fresenius Kabi) and crystalloid hydration solutions $10 \mathrm{~mL} \mathrm{~kg}^{-1} \mathrm{~h}^{-1}$ (Ringer-Acetate, Fresenius Kabi) through infusion pumps 
(Alaris GP; Cardinal Health Care, Rolle, Switzerland). Additional boluses of propofol and/or fentanyl were given if needed. Ventilation was regulated at a positive endexpiratory pressure (PEEP) of $5 \mathrm{~cm} \mathrm{H}_{2} \mathrm{O}$.

Arterial access for blood samples (methemoglobin [MetHb], hemoglobin [Hb] and blood gases) and measurements of mean arterial pressure (MAP) and heart rate (HR) were gained through a $5 \mathrm{Fr}$ catheter (Avanti, Cordis, Cashel, Ireland) placed in the right common carotid artery using the Seldinger technique. A pulmonary arterial catheter (SwanGanz CCOmbo, 7.5 Fr, Edwards Lifesciences, Irvine, CA, USA) was inserted through a $9 \mathrm{Fr}$ catheter (Avanti, Cordis) in the right external jugular vein for measurements of pulmonary arterial pressure, central venous pressure (CVP), continuous cardiac output ( $\mathrm{CCO}$; thermodilution technique) and body temperature. Pulmonary capillary wedge pressure (PCWP) was determined by intermittent occlusion of the pulmonary artery catheter. Venous access for fluid and drug administration was obtained through a central venous catheter in the left external jugular vein (Avanti, Cordis). Hemodynamics were monitored (ICU monitor, AS/3, Datex, Helsinki, Finland) as were ventilation parameters, eg, tidal volume (TV), minute volume (MV), respiratory frequency (RF), inspired fraction of oxygen $\left(\mathrm{FiO}_{2}\right)$, endtidal oxygen concentration $\left(\mathrm{ETO}_{2}\right)$, end-tidal carbon dioxide concentration $\left(\mathrm{ETCO}_{2}\right)$, PEEP and peak inspiratory pressure (PIP), and recorded continuously using the MP150/ Acknowledge 3.9.1 system (BIOPAC systems; Goleta, CA, USA). The urinary bladder was catheterized with a $12 \mathrm{Fr}$ urinary catheter (Foley, Bard Limited, Crawley, UK) through a 3-4 cm midline laparotomy incision. After instrumentation, 5000 IU heparin (LEO Pharma, Malmö, Sweden) was administered iv and the animals were covered with blankets to maintain body temperature. An intervention-free hour followed the surgical preparations in order to reach stable baseline values. After completing the experiments, cardiac arrest was induced under general anesthesia by iv injection of 40 $\mathrm{mM}$ potassium chloride (Braun, Danderyd, Sweden). Termination of circulation was confirmed by ECGregistration, blood pressure and respiratory carbon dioxide measurements.

\section{Drugs}

The thromboxane A2-mimetic 9,11-dideoxy-9 $\alpha, \quad 11 \alpha-$ methanoepoxy $\mathrm{PGF}_{2 \alpha}$, U46619 (Cayman Chemical, MI, USA), was supplied in methyl acetate and diluted in $\mathrm{NaCl}$ $0.9 \%$ to a final concentration of $30 \mu \mathrm{g} \mathrm{mL} L^{-1}$. PDNO was supplied in a solution of $27 \mathrm{mM}$ (SP Process Development,
Södertälje, Sweden). All solutions were administered through syringe pumps. iNO was supplied from a tank (1000 parts per million [ppm] of nitrogen) and introduced to the inspiratory limb of the non-rebreathing ventilator circuit to mix NO with inspired gas in a Servo 300 ventilator (Siemens-Elema, Stockholm, Sweden). A portion of inhaled NO and nitric dioxide continuously passed through a chemiluminescence analyzer to monitor concentrations.

\section{Experimental Protocol}

Three experiments were performed: Dose-response experiments of PDNO at normal pulmonary arterial pressure; Dose-response experiments of PDNO and iNO at pharmacologically increased pulmonary arterial pressure; Single-dose experiments of iNO and PDNO in hypoxic pulmonary vasoconstriction. As many experiments as possible was performed in each animal, but the experiments were terminated if hemodynamic stability was not reached.

\section{Dose-Response Experiments at Normal Pulmonary Arterial Pressure}

Dose-response experiments at normal pulmonary arterial pressure were performed with continuous iv infusions of PDNO doses $\left(\mathrm{n}=10 ; 15,30\right.$ and $\left.60 \mathrm{nmol} \mathrm{kg}{ }^{-1} \mathrm{~min}^{-1}\right)$ in a non-randomized dose arrangement. Hemodynamic parameters were studied at baseline and 7-10 mins after dose augmentation. The animals were hemodynamically stabilized before the next experiment.

\section{Dose-Response Experiments of PDNO and iNO at Pharmacologically Increased Pulmonary Arterial Pressure}

Pulmonary hypertension was induced by continuous iv infusions of U46619 (60-150 $\left.\mathrm{ng} \mathrm{kg}^{-1} \mathrm{~min}^{-1}\right)$ to a target of mean pulmonary arterial pressure (MPAP) at $35-45 \mathrm{~mm}$ $\mathrm{Hg}$. After reaching a steady-state, the pigs received PDNO infusions $\left(\mathrm{n}=6 ; 15,30,45\right.$ and $\left.60 \mathrm{nmol} \mathrm{kg}{ }^{-1} \mathrm{~min}^{-1}\right)$ and inhaled NO $(\mathrm{n}=7 ; 5,10,20,40 \mathrm{ppm})$ in a cross-over nonrandomized fashion; however, three animals received iNO first and five animals received PDNO first. Blood samples (Gem 4000, Instrumental Laboratory, Lexington, MA, USA) and hemodynamic and respiratory parameters were analyzed at baseline, during U46619 infusion prior to drug administration, and at each dose of NO donation and iNO delivery with concurrent U46619 infusion. A washout period of approximately $30 \mathrm{~min}$ was inserted for recovery between the drugs. 
Single-Dose Experiments of iNO and PDNO in Hypoxic Pulmonary Vasoconstriction

The fraction of inspired oxygen was reduced to $0.10-0.11$ to generate hypoxic pulmonary vasoconstriction. The experiment was designed as a cross-over trial with three interventions. The pigs were studied under a five-minute period of inhaled hypoxic gas alone (control condition) and under concurrent infusion of $45 \mathrm{nmol} \mathrm{kg}^{-1} \mathrm{~min}^{-1}$ PDNO or $20 \mathrm{ppm}$ iNO. The order of interventions was randomized. Four animals were used, eight experiments were made since the two animals randomized to start with control conditions died after their first exposure. A third animal was randomized to: PDNO - control condition - iNO and a fourth was randomized to: iNO - control condition - PDNO. Hemodynamic parameters were collected at baseline and after each minute of hypoxia. Blood samples and respiratory parameters were measured at baseline and after 5 mins of hypoxia.

\section{Calculations}

Pulmonary vascular resistance (PVR) was calculated as $(M P A P-P C W P) / C C O$ and systemic vascular resistance (SVR) as $(M A P-C V P) / C C O$ where PCWP and CVP are pulmonary capillary wedge pressure and central venous pressure, respectively. Ppm was converted to $\mathrm{nmol} \mathrm{\textrm {kg } ^ { - 1 }}$ $\min ^{-1}$ using the Ideal Gas Law $p V=n R T$, where $\mathrm{p}, \mathrm{V}, \mathrm{n}$, $\mathrm{R}$ and $\mathrm{T}$ are pressure of the gas, volume of the gas, amount of substance of the gas, universal gas constant, and absolute temperature of the gas, respectively.

\section{Statistical Analysis}

Descriptive data in the dose-response experiments at normal pulmonary pressure are presented as mean \pm standard error of the mean (SEM). Shapiro-Wilk normality test confirmed normal distribution and data were analyzed with linear mixed model for comparison with dose as the repeated factor. Data of U46619-induced pulmonary hypertension experiments are expressed as median and interquartile range (IQR 25th-75th percentile), since the Shapiro-Wilk normality test revealed deviations from normal distribution. Analysis from baseline to U46619 was performed using Wilcoxon signed-rank test. Friedman test was used for analysis of doses within the groups followed by multiple comparisons with Wilcoxon signed-rank test. Mann Whitney $U$-test was used for comparison between the groups. The maximal dose of the drugs and the dose of comparative efficient $\mathrm{NO}$ quantity delivered (PDNO $45 \mathrm{nmol} \mathrm{kg}^{-1} \mathrm{~min}^{-1}$ and iNO $5 \mathrm{ppm}$ ) were analyzed. Posthoc correction of multiple analyses was performed using the Benjamini-Hochberg procedure, a "step-up" sequential method of correction, ${ }^{41}$ with a critical $\mathrm{P}$ value of $<0.05$. SPSS (version 22, IBM Corp., Armonk, NY, USA) was used for statistical analyses. No analyses were made in the experiments of hypoxia-induced vasoconstriction due to the small study group; data are presented as median (IQR). Graphs were created in GraphPad Prism 7 (GraphPad Software, Inc., San Diego, CA, USA).

\section{Results}

\section{Dose-Response Experiments at Normal Pulmonary Arterial Pressure}

PDNO dose-dependently and significantly reduced MPAP, MAP, CVP, PVR and SVR at all doses ( $\mathrm{n}=10$, Table 1).

\section{Dose-Response Experiments of PDNO and iNO at Pharmacologically Increased Pulmonary Arterial Pressure}

MPAP was comparable between the iNO group $(n=7)$ and the PDNO group ( $\mathrm{n}=6)$ at baseline, 24 (IQR 23-26) $\mathrm{mm} \mathrm{Hg}$ versus 24 (IQR 23-27) $\mathrm{mm} \mathrm{Hg.} \mathrm{U46619} \mathrm{increased} \mathrm{MPAP}$ to a stable level at 43 (IQR 37-48) $\mathrm{mm} \mathrm{Hg}$ in the iNO group and 43 (IQR 41-46) $\mathrm{mm} \mathrm{Hg}$ in the PDNO group. Both drugs

Table I Hemodynamics in Dose-Response Experiments at Normal Pulmonary Arterial Pressure

\begin{tabular}{|c|c|c|c|c|c|c|c|c|}
\hline & $\begin{array}{l}\text { HR } \\
\text { (beats } \min ^{-1} \text { ) }\end{array}$ & $\begin{array}{l}\text { MAP } \\
(\mathrm{mm} \mathrm{Hg})\end{array}$ & $\begin{array}{l}\text { MPAP } \\
(\mathrm{mm} \mathrm{Hg})\end{array}$ & $\begin{array}{l}\text { CVP } \\
(\mathrm{mm} \mathrm{Hg})\end{array}$ & $\begin{array}{l}\text { CCO } \\
\left(\mathrm{L} \mathrm{min}^{-1}\right)\end{array}$ & $\begin{array}{l}\text { PCWP } \\
(\mathrm{mm} \mathrm{Hg})\end{array}$ & $\begin{array}{l}\text { PVR } \\
\left(\mathrm{mm} \mathrm{Hg} \min \mathrm{L}^{-1}\right)\end{array}$ & $\begin{array}{l}\text { SVR } \\
\left(\mathrm{mm} \mathrm{Hg}_{\left.\min \mathrm{L}^{-1}\right)}\right.\end{array}$ \\
\hline Baseline & $99 \pm 4$ & $88 \pm 4$ & $22 \pm 1$ & $9.2 \pm 0.5$ & $4.0 \pm 0.2$ & $10.7 \pm 0.4$ & $3.0 \pm 0.4$ & $20.0 \pm 0.8$ \\
\hline $15 \mathrm{nmol} \mathrm{kg}{ }^{-1} \mathrm{~min}^{-1}$ & $111 \pm 6^{a}$ & $7 I \pm 3^{a}$ & $19 \pm 1^{a}$ & $8.5 \pm 0.4^{\mathrm{a}}$ & $3.9 \pm 0.2$ & $10.2 \pm 0.5$ & $2.3 \pm 0.3^{\mathrm{a}}$ & $16.2 \pm 0.7^{\mathrm{a}}$ \\
\hline $30 \mathrm{nmol} \mathrm{kg}{ }^{-1} \mathrm{~min}^{-1}$ & $115 \pm 7^{\mathrm{a}}$ & $67 \pm 2^{\mathrm{a}}$ & $18 \pm 1^{a}$ & $8.3 \pm 0.4^{\mathrm{a}}$ & $3.9 \pm 0.2$ & $9.4 \pm 0.5$ & $2.4 \pm 0.3^{\mathrm{a}}$ & $15.5 \pm 0.7^{\mathrm{a}}$ \\
\hline $60 \mathrm{nmol} \mathrm{kg}{ }^{-1} \mathrm{~min}^{-1}$ & $121 \pm 7^{a}$ & $60 \pm 2^{\mathrm{a}}$ & $18 \pm\left.\right|^{a}$ & $8.2 \pm 0.4^{\mathrm{a}}$ & $3.9 \pm 0.2$ & $9.4 \pm 0.5$ & $2.3 \pm 0.3^{\mathrm{a}}$ & $13.7 \pm 0.7^{\mathrm{a}}$ \\
\hline
\end{tabular}

Notes: Hemodynamic variables at baseline and after 7-10 mins of three doses of 1.2-propanediol mono-organic nitrites (PDNO) in anesthetized pigs ( $\mathrm{n}=10)$. ${ }^{\mathrm{a}} \mathrm{ndicates}$ statistical difference $(P<0.05)$ from baseline. Data are mean \pm standard error of the mean $(S E M)$.

Abbreviations: HR, heart rate; MAP, mean arterial pressure; MPAP, mean pulmonary arterial pressure; CVP, central venous pressure; CCO, continuous cardiac output; PCWP, pulmonary capillary wedge pressure; PVR, pulmonary vascular resistance; SVR, systemic vascular resistance. 
reduced the U46619-induced increase in MPAP dosedependently and significantly (Figure 1). Baseline values of

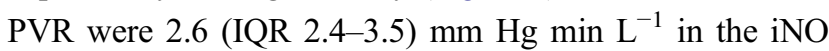

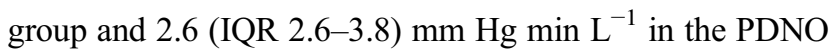
group. U46619 increased the resistance to 8.3 (IQR 6.7-11.7) $\mathrm{mm} \mathrm{Hg} \operatorname{min~} \mathrm{L}^{-1}$ in the iNO group and 9.8 (IQR

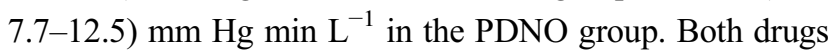
reduced PVR significantly (Figure 1). At baseline, MAP and SVR were 76 (IQR 68-85) and 79 (IQR 71-86) $\mathrm{mm} \mathrm{Hg}$ and 15.0 (IQR 11.8-18.1) and 14.1 (IQR 11.4-16.8) mm Hg min $\mathrm{L}^{-1}$ in the PDNO group and iNO group, respectively. During U46619 infusion, MAP and SVR were 69 (IQR 58-79) and 81 (72-90 IQR) $\mathrm{mmHg}$ and 18.7 (IQR 14.7-22.7) and 17.8

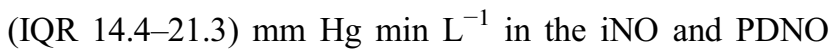
group, respectively. MAP and SVR remained unaffected during iNO administration and were not significantly decreased by PDNO infusion (Figure 1). The PVR:SVR ratio was decreased significantly by both drugs (Table 2). Arterial partial pressure of oxygen increased (Table 3). Methemoglobin increased significantly during iNO administration (Figure 1, $\mathrm{P}<0.05$ in Friedman test). When comparing the drugs at equivalent $\mathrm{NO}$ quantity delivered (iNO 5 ppm and PDNO $45 \mathrm{nmol} \mathrm{kg}^{-1} \mathrm{~min}^{-1}$ ), PDNO decreased PVR $(\mathrm{P}<0.05)$ and $\mathrm{SVR}(\mathrm{P}<0.05)$ more than iNO.

\section{Single-Dose Experiments of iNO and PDNO in Hypoxic Pulmonary \\ Vasoconstriction}

Acute hypoxia increased MPAP, and iNO (n=2) and PDNO $(\mathrm{n}=2)$ markedly suppressed this increase (Figure 2). MAP decreased in all groups (Figure 2). The decrease in PVR: $\mathrm{SVR}$ ratio was comparable between iNO and PDNO groups (Figure 2).

\section{Discussion}

In this pilot study, we have made a direct comparison of short-term pulmonary and systemic effects of the iv organic nitrite NO-donor PDNO and iNO, the gold standard pulmonary vasodilator, in two piglet models of acute pulmonary hypertension. In agreement with prior studies, iNO selectively dilated the pulmonary circulation in both models of acute pulmonary hypertension. The novel NO donor PDNO exhibited a potent dose-dependent pulmonary vasodilatory effect in the model of pharmacologically induced acute pulmonary hypertension and completely counteracted the hypoxiainduced pulmonary vasoconstriction.
Since the toxic effects of NO are partly dose-dependent, it is essential to use the lowest effective dose. The appropriate dose of iNO is, however, debated. Recommended start dose of iNO in infants with persistent pulmonary hypertension is $10 \mathrm{ppm}$ and the maximal dose is $20 \mathrm{ppm}$. In peri-postoperative treatment associated with heart surgery in adults, the recommended start dose is $20 \mathrm{ppm}$ and the maximal dose is 40 ppm. ${ }^{42}$ In this study, doses of iNO were based on clinically relevant doses and on prior porcine studies of hypoxic pulmonary hypertension. ${ }^{13,43}$ The current report indicates that doses above 5 ppm exert minimal additional pulmonary vasodilation and that iNO in a clinical maximal dose is not capable of completely reversing an acute rise in pulmonary arterial pressure. Similar findings have been presented by other authors. ${ }^{43,44}$ However, it seems possible, based on the present data and the dose-dependent correlation of PDNO, that higher doses of PDNO may completely reverse an acute increase in pulmonary arterial pressure. A further dose elevation to confirm this was not performed in this study in order to sustain a clinically relevant MAP of minimum $60 \mathrm{~mm} \mathrm{Hg}$.

Administration of NO could also be problematic due to methemoglobin formation. ${ }^{36-38}$ Methemoglobin is a product of oxidized nitrosyl hemoglobin, generated from NO combined with hemoglobin. The affinity of NO for hemoglobin is 1500 times that of carbon monoxide ${ }^{45}$ and the product impairs the capability of erythrocytes to carry and deliver oxygen to tissue. ${ }^{46}$ iNO seems to be safe from significant methemoglobin formation when given at doses less than $80 \mathrm{ppm}^{13,18}$ In healthy people, methemoglobin levels range from $0 \%$ to $3 \%$, but even concentrations less than $3 \%$ have been associated with increased mortality in critically ill patients treated with iNO. ${ }^{25}$ In our settings, methemoglobin levels correlated with the quantity of supplied NO, regardless of route of administration (Figure 1E). Hence, our data indicate that the risk of methemoglobinemia in short-term administration of PDNO doses up to $60 \mathrm{nmol} \mathrm{kg}{ }^{-1} \min ^{-1}$ would be lower than during inhalation of clinically accepted iNO doses. In a prior study, PDNO administration at $60 \mathrm{nmol} \mathrm{kg}{ }^{-1} \min ^{-1}$ over $6 \mathrm{hrs}$ increased methemoglobin by $0.3 \%$, which suggests that, even in long-term infusions of PDNO, there is a low risk of methemoglobin accumulation. ${ }^{47}$ Notably, iNO at 40 ppm over $30 \mathrm{~h}$ does not cause excessive methemoglobinemia, ${ }^{48}$ which makes it probable that methemoglobin levels reach a plateau in long-term NO administration.

In the present study, the lowest dose of PDNO (15 $\mathrm{nmol} \mathrm{kg}^{-1} \mathrm{~min}^{-1}$ ) had a comparable effect on pulmonary vascular resistance to that of iNO $40 \mathrm{ppm}$ (449 $\mathrm{nmol} \mathrm{NO} \mathrm{kg}^{-1}$ $\min ^{-1}$, maximal clinical dose in adults). The reason behind 

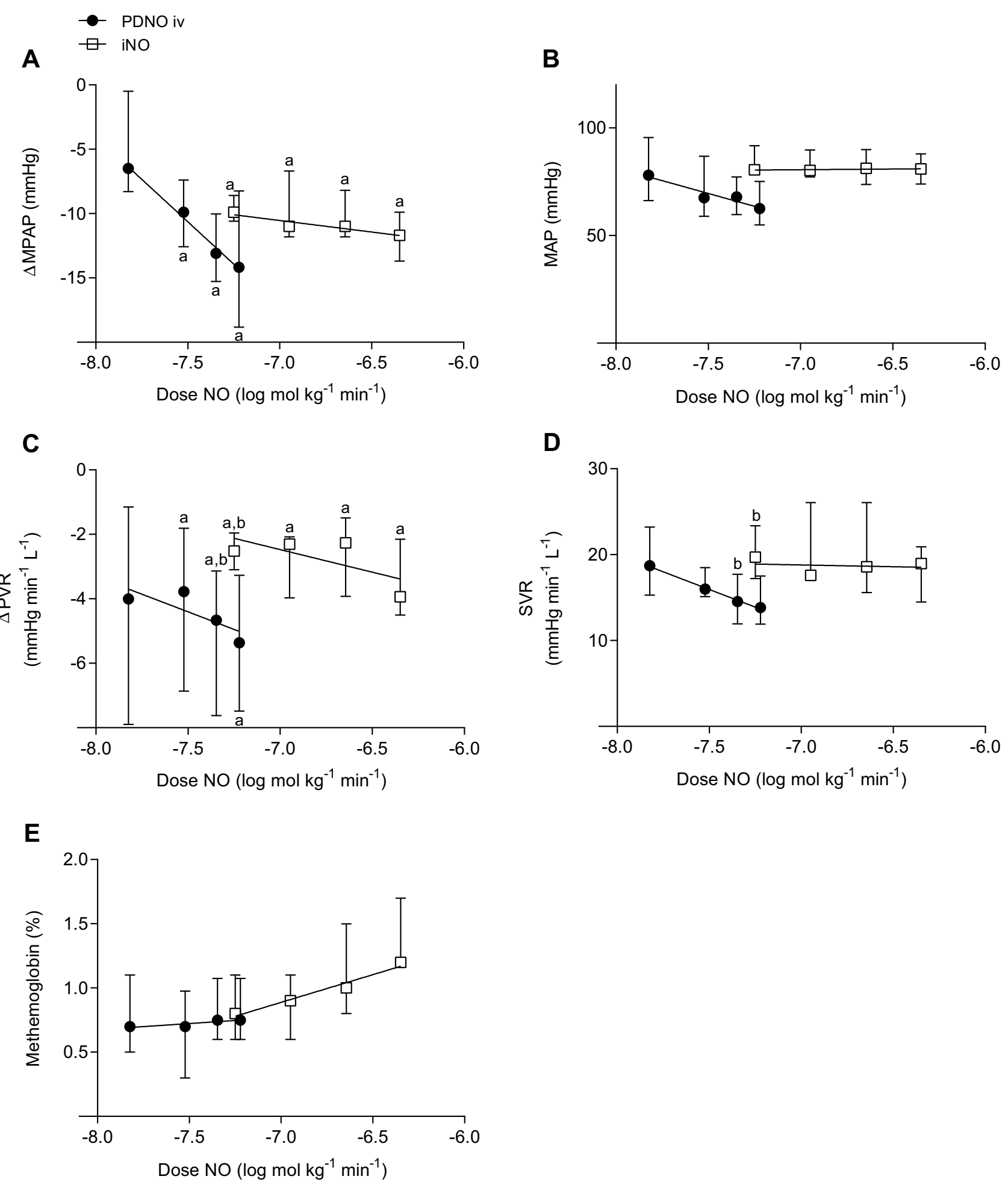

Figure I Decrease in mean pulmonary arterial pressure (MPAP, A), mean systemic arterial pressure (MAP, B), absolute decrease in pulmonary vascular resistance (PVR, C), systemic vascular resistance (SVR, D) and percentage of methemoglobin in arterial blood (panel E) during iv administration of I,2-propanediol mono-organic nitrites (PDNO, n=6) and inhalation of nitric oxide (iNO, $n=7$ ) in four doses in anesthetized pigs. ${ }^{a}$ Denotes significant difference from $U 46619 .{ }^{b}$ Represents significant difference between comparable nitric oxide (NO) delivery dose. No statistical analysis was performed on PDNO $15 \mathrm{nmol} \mathrm{kg}^{-1} \mathrm{~min}^{-1}$, due to only three observations caused by syringe pump problems. Data are medians and interquartile ranges.

a more potent pulmonary vasodilation of an iv-administered drug compared to iNO is probably due to a capability to affect larger pulmonary vessels. ${ }^{26,49}$ The mechanism is not fully understood but Guarin et $\mathrm{al}^{26}$ proposed a diameter dependent process of converting NO signal to smooth muscle relaxation or, alternatively, that the diffusion of NO to place 
Table 2 Hemodynamics During Pharmacologically Induced Pulmonary Hypertension

\begin{tabular}{|c|c|c|c|c|c|}
\hline & HR (beats $\min ^{-1}$ ) & CVP (mm Hg) & $\operatorname{CCO}\left(\mathrm{L} \mathrm{min}^{-1}\right)$ & PCWP (mm Hg) & PVR/SVR \\
\hline \multicolumn{6}{|l|}{ iNO (ppm) } \\
\hline Baseline & $103(95-120)$ & $10.8(9.0-10.9)$ & $4.6(3.8-5.1)$ & $11.0(10.0-13.0)$ & $0.2(0.2-0.2)$ \\
\hline U46619 & $114(93-125)$ & $11.6(11.3-13.8)^{\mathrm{a}}$ & $3.3(3.1-4.4)^{\mathrm{a}}$ & $11.0(10.0-12.0)$ & $0.5(0.4-0.5)^{\mathrm{a}}$ \\
\hline U46619 + iNO 5 & $101(84-110)^{b}$ & $11.2(10.5-12.5)^{\mathrm{b}}$ & $3.3(3.1-3.9)$ & $12.0(11.0-12.0)$ & $0.3(0.3-0.4)^{\mathrm{b}}$ \\
\hline $\mathrm{U} 46619+\mathrm{iNO} 10$ & $100(80-106)^{\mathrm{b}}$ & $11.6(10.5-12.4)^{\mathrm{b}}$ & $3.7(2.8-3.9)$ & $11.0(11.0-12.0)$ & $0.3(0.2-0.4)^{\mathrm{b}}$ \\
\hline $\mathrm{U} 46619+\mathrm{iNO} 20$ & $97(78-106)^{\mathrm{b}}$ & $1 \mathrm{I} .3(10.8-1 \mathrm{I} .8)^{\mathrm{b}}$ & $3.4(2.7-4.2)$ & $11.0(11.0-13.0)$ & $0.3(0.2-0.3)^{\mathrm{b}}$ \\
\hline $\mathrm{U} 46619+\mathrm{iNO} 40$ & $96(78-101)^{\mathrm{b}}$ & $1 \mathrm{I} .1(10.7-1 \mathrm{I} .7)^{\mathrm{b}, \mathrm{c}}$ & $3.6(3.3-4.2)$ & $11.0(11.0-14.0)$ & $0.2(0.2-0.3)^{b, c}$ \\
\hline \multicolumn{6}{|l|}{ PDNO $\left(\mathrm{nmol} \mathrm{kg}^{-1} \mathrm{~min}^{-1}\right)$} \\
\hline Baseline & $98(83-106)$ & $10.9(9.3-11.1)$ & $3.9(3.8-5.0)$ & $12.0(10.0-13.0)$ & $0.2(0.2-0.2)$ \\
\hline U46619 & $110(100-119)^{\mathrm{a}}$ & $12.7(11.5-13.7)^{\mathrm{a}}$ & $3.4(2.6-3.9)^{\mathrm{a}}$ & $11.5(10.5-13.0)$ & $0.5(0.5-0.7)^{\mathrm{a}}$ \\
\hline U46619 + PDNO 15 & $94(9 \mid-121)$ & $10.4(10.2-11.3)$ & $3.0(2.7-3.5)$ & $12.0(9.0-13.0)$ & $0.3(0.3-0.4)$ \\
\hline U46619 + PDNO 30 & $95(93-114)$ & $10.6(10.1-11.2)^{b}$ & $3.7(3.3-4.1)$ & $11.0(10.5-12.3)$ & $0.3(0.3-0.4)^{\mathrm{b}}$ \\
\hline U46619 + PDNO 45 & $102(94-115)$ & $10.3(9.2-10.8)^{\mathrm{b}}$ & $4.0(3.4-4.7)$ & $11.5(10.8-12.3)$ & $0.3(0.3-0.4)^{\mathrm{b}}$ \\
\hline U46619 + PDNO 60 & $102(95-114)$ & $10.2(9.3-10.8)^{\mathrm{b}, \mathrm{c}}$ & $4.0(3.4-4.2)$ & $11.0(10.8-12.3)$ & $0.3(0.3-0.4)^{\mathrm{b}, \mathrm{c}}$ \\
\hline
\end{tabular}

Notes: Hemodynamic parameters at baseline, at U46619 administration (60-150 ng kg-1 $\mathrm{min}^{-1}$ iv), after 7-10 mins of four doses of I,2-propanediol mono-organic nitrites infusion (PDNO iv, $n=6$ ) and after 7-10 mins of four doses of inhaled nitric oxide (iNO, n=7) in anesthetized pigs. ${ }^{a}$ Indicates statistical difference from baseline to U466।9.

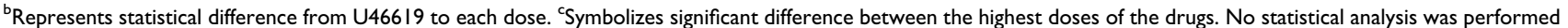
on PDNO $15 \mathrm{nmol} \mathrm{kg}^{-1} \mathrm{~min}^{-1}$, due to only three observations caused by syringe pump problems. Data are median and interquartile ranges (IQR).

Abbreviations: HR, heart rate; CVP, central venous pressure; CCO, continuous cardiac output; PCWP, pulmonary capillary wedge pressure; PVR, pulmonary vascular resistance; SVR, systemic vascular resistance.

Table 3 Arterial Blood Gases During Pharmacologically Induced Pulmonary Hypertension

\begin{tabular}{|c|c|c|c|c|}
\hline & $\mathbf{p H}$ & $\mathrm{PCO}_{2}(\mathrm{kPa})$ & $\mathrm{PO}_{2}(\mathrm{kPa})$ & $\mathrm{Hb}\left(\mathrm{g} \mathrm{L}^{-1}\right)$ \\
\hline \multicolumn{5}{|l|}{ iNO (ppm) } \\
\hline Baseline & $7.53(7.49-7.60)$ & $4.9(4.5-5.0)$ & I3.4 (I2.0-13.4) & $80(75-80)$ \\
\hline U46619 & $7.52(7.48-7.56)$ & $4.5(4.3-4.7)$ & $12.1(9.9-13.4)$ & $80(76-84)$ \\
\hline U46619 + iNO 5 & $7.53(7.5 \mathrm{I}-7.57)^{\mathrm{b}}$ & $4.2(4 . I-4.5)$ & $13.7(12.0-14.6)^{\mathrm{b}}$ & $80(75-84)$ \\
\hline U46619 + iNO 10 & $7.53(7.5 \mathrm{I}-7.58)^{\mathrm{b}}$ & $4.1(3.9-4.5)$ & $12.8(12.0-14.7)^{\mathrm{b}}$ & $80(76-84)$ \\
\hline U466I9 + iNO 20 & $7.54(7.5 \mathrm{I}-7.57)^{\mathrm{b}}$ & $4.2(3.9-4.5)$ & $13.0(12.4-14.5)^{\mathrm{b}}$ & $79(76-85)$ \\
\hline $\mathrm{U} 46619+\mathrm{iNO} 40$ & $7.54(7.5 \mathrm{I}-7.58)^{\mathrm{b}}$ & $4.2(4 . I-4.5)$ & $12.9(12.4-15.0)^{\mathrm{b}}$ & $79(7 \mid-85)$ \\
\hline \multicolumn{5}{|l|}{ PDNO $\left(\mathrm{nmol} \mathrm{kg}^{-1} \mathrm{~min}^{-1}\right)$} \\
\hline Baseline & $7.56(7.49-7.57)$ & $4.5(4.4-4.9)$ & $13.9(\mid 1.7-14.1)$ & $74(70-76)$ \\
\hline U46619 & $7.52(7.47-7.55)$ & $4.4(4.2-4.8)$ & II.3 $(9.4-13.0)^{\mathrm{a}}$ & $79(73-82)^{a}$ \\
\hline U46619 + PDNO 15 & 7.55 (7.48-7.57) & $4.3(4.1-4.8)$ & II.8 (II.0-11.9) & $76(74-76)$ \\
\hline U46619 + PDNO 30 & $7.57(7.48-7.59)^{\mathrm{b}}$ & $4.2(3.9-4.7)$ & $12.6(11.8-13.6)^{b}$ & $75(70-84)$ \\
\hline U46619 + PDNO 45 & $7.56(7.48-7.59)^{b}$ & $4.2(3.9-4.7)$ & $12.8(\mid 2.3-14.0)^{\mathrm{b}}$ & $74(69-8 I)$ \\
\hline U46619 + PDNO 60 & $7.56(7.49-7.60)^{\mathrm{b}}$ & $4.2(4.1-4.7)$ & $12.6(12.1-14.0)^{\mathrm{b}}$ & 74 (69-77) \\
\hline
\end{tabular}

Notes: Arterial blood gases at baseline, at U46619 administration (60-150 ng kg ${ }^{-1} \mathrm{~min}^{-1}$ ), after 7-10 mins of four doses of I,2-propanediol mono-organic nitrites infusion

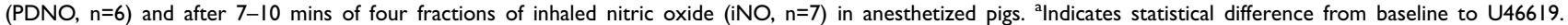
${ }^{b}$ Represents statistical difference from $U 46619$ to each dose. No statistical analysis was performed on PDNO $15 \mathrm{nmol} \mathrm{kg}^{-1} \mathrm{~min}^{-1}$, due to only three observations caused by syringe pump problems. Data are median and interquartile ranges (IQR).

Abbreviations: $\mathrm{pCO}_{2}$, arterial partial pressure of carbon dioxide; $\mathrm{pO}_{2}$, arterial partial pressure of oxygen; Hb, hemoglobin.

of action might be affected by the geometric vascular relationships alone (ie, vessel lumen area, size of vessel wall, vascular transit time). Regardless of mechanism, the present data support the assumption of a more potent pulmonary vasodilation by an iv NO donor than of iNO and strengthens the belief in a pulmonary selective iv NO donor in severely diseased humans when iNO is not sufficient.
Clinically available NO donors are, however, nonselective and cause adverse systemic effects. Evidence that PDNO has pulmonary favorable qualities was first provided by Nilsson et $\mathrm{al}^{34}$ in a rabbit model of U46619-induced pulmonary hypertension. PDNO, in contrast to other organic nitrites, showed some selective pulmonary vasodilatory action, verified by concentration of exhaled NO and systemic 


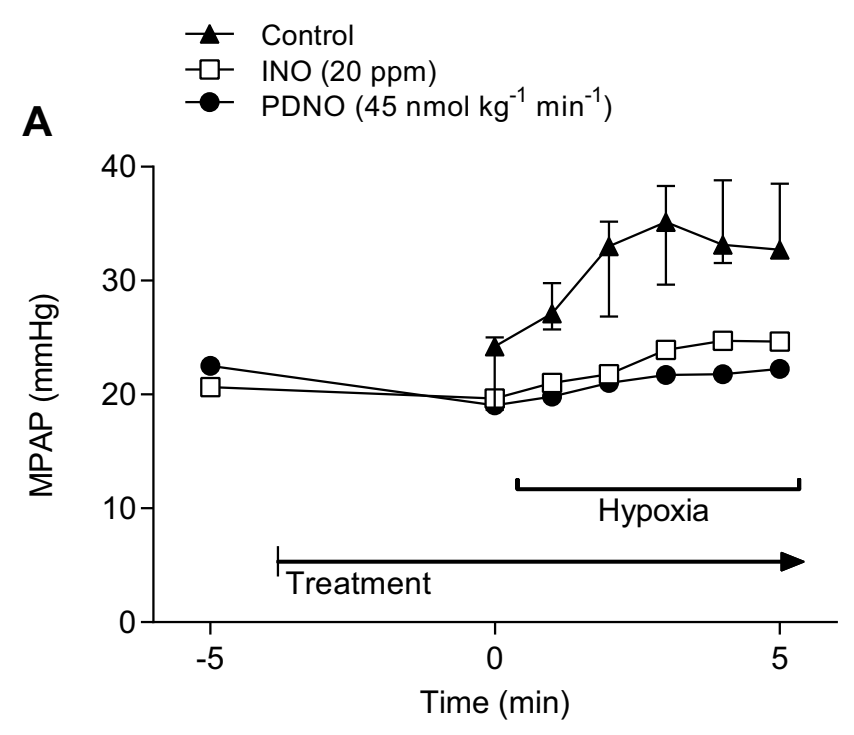

B

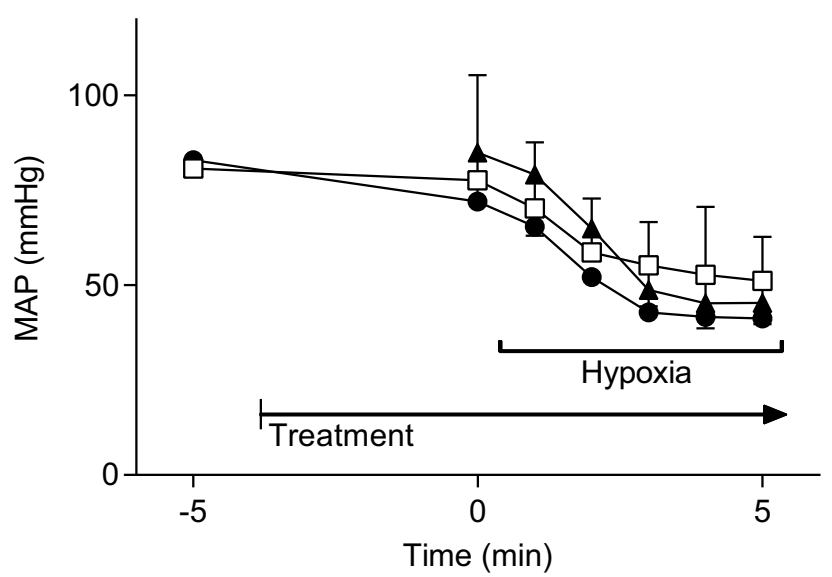

C

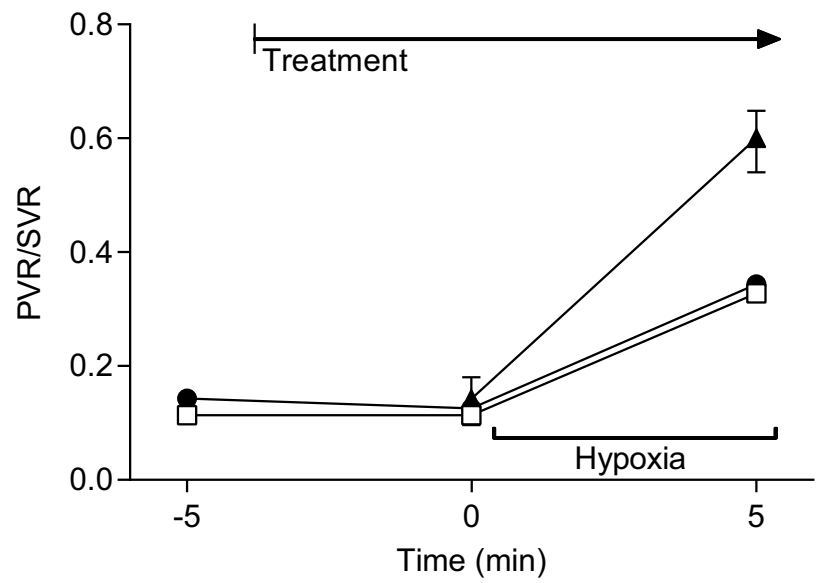

Figure 2 Mean pulmonary arterial pressure (MPAP, A), mean systemic arterial pressure (MAP, B), and ratio of pulmonary and systemic vascular resistances (PVR/SVR, C) at fraction of inspired oxygen $0.10-0.11$ for 5 mins (hypoxia). Pigs received iv administration of $45 \mathrm{nmol} \mathrm{kg}^{-1} \mathrm{~min}^{-1}$ I,2-propanediol mono-organic nitrites (PDNO, n=2), $20 \mathrm{ppm}$ of inhaled nitric oxide (iNO, $n=2$ ) or hypoxia alone (control, $n=4$ ). Data are medians and interquartile ranges (IQR, only in the control group). blood pressure measurements. The present data support this finding. PDNO, in contrast to iNO, caused systemic effects, but the systemic pressure remained at an acceptable clinical level and the systemic resistance did not decrease significantly. The PVR:SVR ratio, used as a measurement of pulmonary selectivity in prior studies, ${ }^{43,50}$ decreased to baseline values, thus supporting that the main vasodilatory effect of PDNO in the present models was in the pulmonary circulation.

This pilot study has limitations. The number of animals was low, limiting the statistical power, especially in the hypoxia-induced pulmonary hypertension experiments. These data must therefore be interpreted with caution. The study was not designed as a superiority or non-inferiority study but aimed at exploring the pharmacology of PDNO compared to iNO. Furthermore, the pathogenesis of acute pulmonary hypertension is complex. It should be acknowledged that this study was implemented on healthy lungs and is not directly applicable to severely diseased lungs. However, it is known that thromboxanes and hypoxia are crucial elements of acute pulmonary hypertension in sepsis. ${ }^{51}$ In diseases where regional ventilation and perfusion are mismatched, iNO may enhance oxygenation more than iv NO due to redistribution of pulmonary blood flow from nonventilated lung segments to ventilated lung segments, although vasodilation is more prominent with iv $\mathrm{NO}^{52}$ However, this effect is temporary. ${ }^{18}$ There is also a risk that iv NO donors cause enhanced ventilation-perfusion mismatch. The arterial oxygenation was however unchanged by PDNO in the present study and in a study of PDNO in acute experimental pulmonary embolism. ${ }^{39}$

In addition, the investigators were not blinded, and the sequence of drugs administered in the U46619-experiments was not randomized. It is nevertheless unlikely that randomization or a cumulative effect of the consecutive administration of drugs would affect the outcome since the half-lives of the drugs are short and a washout period for stabilization of hemodynamic parameters was inserted between the administrations. However, the reactivity of the vasculature may alter over time in these models.

\section{Conclusion}

Intravenous PDNO was shown to be a potent pulmonary vasodilator without severe short-term side effects in acute pulmonary hypertension in pigs. PDNO was more efficient and more potent than the clinically available pulmonary selective vasodilator iNO. In addition, iNO slightly increased 
the fraction of methemoglobin, but the methemoglobin levels were within clinically acceptable limits. This study suggests that administration of the iv NO donor PDNO in acute pulmonary hypertension may be favorable. However, longterm efficacy and safety need to be further investigated.

\section{Abbreviations}

ARDS, acute respiratory distress syndrome; $\mathrm{pCO}_{2}$, arterial partial pressure of carbon dioxide; $\mathrm{pO}_{2}$, arterial partial pressure of oxygen; CVP, central venous pressure; $\mathrm{CCO}$, continuous cardiac output; $\mathrm{ETCO}_{2}$, end-tidal carbon dioxide concentration; $\mathrm{ETO}_{2}$, end-tidal oxygen concentration; $\mathrm{FIO}_{2}$, Fraction of Inspired oxygen; HR, heart rate; iNO, inhaled nitric oxide; IQR, interquartile range; IM, intramuscular; iv, intravenous; MAP, mean arterial pressure; MPAP, mean pulmonary arterial pressure; MetHb, methemoglobin; MV, minute volume; NO, nitric oxide; ppm, parts per million; PEEP, positive end-expiratory pressure; PIP, peak inspiratory pressure; PCWP, pulmonary capillary wedge pressure; PVR, pulmonary vascular resistance; SVR, systemic vascular resistance; TV, tidal volume; U46619, thromboxane A2-mimetic 9,11-dideoxy-9 $\alpha, 11 \alpha$ methanoepoxy $\mathrm{PGF}_{2 \alpha} ; \mathrm{PDNO}, 1,2$-propanediol monoorganic nitrites.

\section{Acknowledgments}

The authors would like to express gratitude to the late professor Lars E. Gustafsson for excellent guidance during the experiments and special thanks to RN Nina Adolfsson for invaluable help with coordination in the laboratory.

\section{Funding}

The study was financially supported by Attgeno $A B$, Stockholm, Sweden (clinical development of PDNO) and the Swedish Society for Medical Research.

\section{Disclosure}

Anna Stene Hurtsén reports grants from Attgeno AB, during the conduct of the study. Kristofer F Nilsson wishes to declare potential financial competing interests due to his roles as co-applicant in three international patents (US 8,552,068, US 8,030,511 and EP 2004576), and coownership, consultancy and former board membership of Attgeno $\mathrm{AB}$, pertaining to the current subject matter; reports grants and personal fees from Attgeno AB, Stockholm, Sweden, during the conduct of the study; and has another patent pending: UK Patent Application No. 1819298.9. The authors report no other conflicts of interest in this work.

\section{References}

1. Hatano S, Strasser T, World Health Organization. Primary pulmonary hypertension: report on a WHO meeting, Geneva, 15-17 October / 1973 edited by Shuichi Hatano and Toma Strasser. World Health Organization; 1975. Available from: http://www.who.int/iris/handle/ 10665/39094. Accessed February 5, 2020.

2. Stamm JA, McVerry BJ, Mathier MA, Donahoe MP, Saul MI, Gladwin MT. Doppler-defined pulmonary hypertension in medical intensive care unit patients: retrospective investigation of risk factors and impact on mortality. Pulm Circ. 2011;1(1):95-102. doi:10.4103/20458932.78104

3. Kaestner M, Schranz D, Warnecke G, Apitz C, Hansmann G, Miera O. Pulmonary hypertension in the intensive care unit. Expert consensus statement on the diagnosis and treatment of paediatric pulmonary hypertension. The European Paediatric Pulmonary Vascular Disease Network, endorsed by ISHLT and DGPK. Heart Br Card Soc. 2016;102 Suppl 2:ii57-66.

4. Levitzky MG. Blood flow to the lung. In: Pulmonary Physiology. 9th ed. New York, NY: McGraw-Hill Education;2017. Available from: accessmedicine. $\mathrm{mhmedical}$.com/content.aspx?aid=1149865170. Accessed December 21, 2017

5. Moloney ED, Evans TW. Pathophysiology and pharmacological treatment of pulmonary hypertension in acute respiratory distress syndrome. Eur Respir J. 2003;21(4):720-727. doi:10.1183/09031936.03.00120102

6. Smulders YM. Pathophysiology and treatment of haemodynamic instability in acute pulmonary embolism: the pivotal role of pulmonary vasoconstriction. Cardiovasc Res. 2000;48(1):23-33. doi:10.10 16/S0008-6363(00)00168-1

7. Via G, Braschi A. Pathophysiology of severe pulmonary hypertension in the critically ill patient. Minerva Anestesiol. 2004;70(4):233-237.

8. Matthews JC, McLaughlin V. Acute right ventricular failure in the setting of acute pulmonary embolism or chronic pulmonary hypertension: a detailed review of the pathophysiology, diagnosis, and management. Curr Cardiol Rev. 2008;4(1):49-59. doi:10.2174/157340308783565384

9. Vlahakes GJ, Turley K, Hoffman JI. The pathophysiology of failure in acute right ventricular hypertension: hemodynamic and biochemical correlations. Circulation. 1981;63(1):87-95. doi:10.1161/01. CIR.63.1.87

10. Ignarro LJ, Buga GM, Wood KS, Byrns RE, Chaudhuri G. Endothelium-derived relaxing factor produced and released from artery and vein is nitric oxide. Proc Natl Acad Sci U S A. 1987;84 (24):9265-9269. doi:10.1073/pnas.84.24.9265

11. Palmer RM, Ferrige AG, Moncada S. Nitric oxide release accounts for the biological activity of endothelium-derived relaxing factor. Nature. 1987;327(6122):524-526. doi:10.1038/327524a0

12. Hughes MN. Chemistry of nitric oxide and related species. Methods Enzymol. 2008;436:3-19.

13. Frostell C, Fratacci MD, Wain JC, Jones R, Zapol WM. Inhaled nitric oxide. A selective pulmonary vasodilator reversing hypoxic pulmonary vasoconstriction. Circulation. 1991;83(6):2038-2047. doi:10.1161/01. CIR.83.6.2038

14. Albert M, Corsilli D, Williamson DR, et al. Comparison of inhaled milrinone, nitric oxide and prostacyclin in acute respiratory distress syndrome. World J Crit Care Med. 2017;6(1):74-78. doi:10.5492/ wjccm.v6.i1.74

15. Beghetti M, Spahr-Schopfer I, Mensi N, Morel DR, Rimensberger PC. Effects of inhaled nitric oxide and intravenous magnesium sulphate, alone and in combination, in a porcine model of hypoxic pulmonary hypertension. Med Sci Monit Int Med J Exp Clin Res. 2003;9(6): BR193-198.

16. Bigatello LM, Hurford WE, Kacmarek RM, Roberts JD, Zapol WM. Prolonged inhalation of low concentrations of nitric oxide in patients with severe adult respiratory distress syndrome. Effects on pulmonary hemodynamics and oxygenation. Anesthesiology. 1994;80 (4):761-770. doi:10.1097/00000542-199404000-00007 
17. Rossaint R, Falke KJ, López F, Slama K, Pison U, Zapol WM. Inhaled nitric oxide for the adult respiratory distress syndrome. $N$ Engl J Med. 1993;328(6):399-405. doi:10.1056/NEJM199302113280605

18. Karam O, Gebistorf F, Wetterslev J, Afshari A. The effect of inhaled nitric oxide in acute respiratory distress syndrome in children and adults: a Cochrane Systematic Review with trial sequential analysis. Anaesthesia. 2017;72(1):106-117. doi:10.1111/anae.13628

19. Pedersen J, Hedegaard ER, Simonsen U, Krüger M, Infanger M, Current GD. Future treatments for persistent pulmonary hypertension in the Newborn. Basic Clin Pharmacol Toxicol. 2018;123 (4):392-406. doi:10.1111/bcpt.13051

20. Monsalve-Naharro JÁ, Domingo-Chiva E, García Castillo S, CuestaMontero P, Jiménez-Vizuete JM. Inhaled nitric oxide in adult patients with acute respiratory distress syndrome. Farm Hosp. 2017;41 (2):292-312.

21. Claesson J, Freundlich M, Gunnarsson I, et al. Scandinavian clinical practice guideline on fluid and drug therapy in adults with acute respiratory distress syndrome. Acta Anaesthesiol Scand. 2016;60 (6):697-709. doi:10.1111/aas.2016.60.issue-6

22. Meade MO, Jacka MJ, Cook DJ, et al. Survey of interventions for the prevention and treatment of acute respiratory distress syndrome. Crit Care Med. 2004;32(4):946-954. doi:10.1097/01.CCM.0000120056. 76356.AD

23. Beckman JS, Beckman TW, Chen J, Marshall PA, Freeman BA. Apparent hydroxyl radical production by peroxynitrite: implications for endothelial injury from nitric oxide and superoxide. Proc Natl Acad Sci U S A. 1990;87(4):1620-1624. doi:10.1073/pnas.87.4.1620

24. Lundin S, Mang H, Smithies M, Stenqvist O, Frostell C. Inhalation of nitric oxide in acute lung injury: results of a European multicentre study. The European Study Group of Inhaled Nitric Oxide. Intensive Care Med. 1999;25(9):911-919. doi:10.1007/s001340050982

25. Rolley L, Bandeshe H, Boots RJ. "Safe" methaemoglobin concentrations are a mortality risk factor in patients receiving inhaled nitric oxide. Anaesth Intensive Care. 2011;39(5):919-925. doi:10.1177/ 0310057X1103900519

26. Guarín M, Dawson CA, Nelin LD. The arterial site of action of nitric oxide in the neonatal pig lung determined by microfocal angiography. Lung. 2001;179(1):43-55. doi:10.1007/s004080000046

27. Rimar S, Gillis CN. Selective pulmonary vasodilation by inhaled nitric oxide is due to hemoglobin inactivation. Circulation. 1993;88 (6):2884-2887. doi:10.1161/01.CIR.88.6.2884

28. Miller MR, Megson IL. Recent developments in nitric oxide donor drugs. Br J Pharmacol. 2007;151(3):305-321. doi:10.1038/sj.bjp.0707224

29. Cockrill BA, Kacmarek RM, Fifer MA, et al. Comparison of the effects of nitric oxide, nitroprusside, and nifedipine on hemodynamics and right ventricular contractility in patients with chronic pulmonary hypertension. Chest. 2001;119(1):128-136. doi:10.1378/chest.119.1.128

30. Butler AR, Glidewell C, McGinnis J, Bisset WI. Further investigations regarding the toxicity of sodium nitroprusside. Clin Chem. 1987;33(4):490-492. doi:10.1093/clinchem/33.4.490

31. Agvald P, Adding LC, Gustafsson LE, Persson MG. Nitric oxide generation, tachyphylaxis and cross-tachyphylaxis from nitrovasodilators in vivo. Eur J Pharmacol. 1999;385(2-3):137-145. doi:10.1016/S00142999(99)00720-7

32. Tilton RG, Brock TA, Dixon RA. Therapeutic potential of endothelin receptor antagonists and nitric oxide donors in pulmonary hypertension. Expert Opin Investig Drugs. 2001;10(7):1291-1308. doi:10.1517/13543784.10.7.1291

33. Bauer JA, Nolan T, Fung HL. Vascular and hemodynamic differences between organic nitrates and nitrites. J Pharmacol Exp Ther. 1997;280(1):326-331.

34. Nilsson KF, Lundgren M, Agvald P, Adding LC, Linnarsson D, Gustafsson LE. Formation of new bioactive organic nitrites and their identification with gas chromatography-mass spectrometry and liquid chromatography coupled to nitrite reduction. Biochem Pharmacol. 2011;82(3):248-259. doi:10.1016/j.bcp.2011.04.005
35. Nilsson KF, Goździk W, Frostell C, et al. Organic mononitrites of 1,2-propanediol act as an effective NO-releasing vasodilator in pulmonary hypertension and exhibit no cross-tolerance with nitroglycerin in anesthetized pigs. Drug Des Devel Ther. 2018;12:685-694. doi:10.2147/DDDT

36. Abman SH, Kinsella JP. Inhaled ethyl nitrite gas for persistent pulmonary hypertension in infants. Lancet Lond Engl. 2002;360 (9350):2076-2077; author reply 2077. doi:10.1016/S0140-6736(02) 12000-9

37. Lavon O, Bentur Y. Does amyl nitrite have a role in the management of pre-hospital mass casualty cyanide poisoning? Clin Toxicol Phila Pa. 2010;48(6):477-484. doi:10.3109/15563650. 2010.505573

38. Moya MP, Gow AJ, Califf RM, Goldberg RN, Stamler JS. Inhaled ethyl nitrite gas for persistent pulmonary hypertension of the newborn. Lancet Lond Engl. 2002;360(9327):141-143. doi:10.1016/ S0140-6736(02)09385-6

39. Nilsson KF, Gustafsson LE. Treatment with new organic nitrites in pulmonary hypertension of acute experimental pulmonary embolism. Pharmacol Res Perspect. 2019;7(1):e00462. doi:10.1002/prp2.2019.7. issue-1

40. Directive 2010/63/EU of the European Parliament and of the Council of 22 September 2010 on the protection of animals used for scientific purposes. Available from: http://eur-lex.europa.eu/legal-content/EN/ TXT/PDF/?uri=CELEX:32010L0063\&rid=1. Accessed February 5, 2020.

41. Benjamini Y, Hochberg Y. Controlling the false discovery rate: a practical and powerful approach to multiple testing. $J$ R Stat Soc Ser B Methodol. 1995;57(1):289-300.

42. INOmax: EPAR - Scientific discussion. May 2006. Available from: https://www.ema.europa.eu/en/documents/scientific-discussion/ino max-epar-scientific-discussion_en.pdf. Accessed May 23, 2019.

43. Etches PC, Finer NN, Barrington KJ, Graham AJ, Chan WK. Nitric oxide reverses acute hypoxic pulmonary hypertension in the newborn piglet. Pediatr Res. 1994;35(1):15-19. doi:10.1203/00006450-19940 1000-00004

44. Guthrie SO, Walsh WF, Auten K, Clark RH. Initial dosing of inhaled nitric oxide in infants with hypoxic respiratory failure. $J$ Perinatol off $J$ Calif Perinat Assoc. 2004;24(5):290-294.

45. Gibson QH, Roughton FJ. The kinetics and equilibria of the reactions of nitric oxide with sheep haemoglobin. J Physiol. 1957;136 (3):507-524. doi:10.1113/jphysiol.1957.sp005777

46. Wright RO, Lewander WJ, Woolf AD. Methemoglobinemia: etiology, pharmacology, and clinical management. Ann Emerg Med. 1999;34(5):646-656. doi:10.1016/S0196-0644(99)70167-8

47. Nilsson KF, Sandin J, Gustafsson LE, Frithiof R. The novel nitric oxide donor PDNO attenuates ovine ischemia-reperfusion induced renal failure. Intensive Care Med Exp. 2017;5(1):29. doi:10.1186/ s40635-017-0143-4

48. Albert J, Harbut P, Zieliński S, et al. Prolonged exposure to inhaled nitric oxide does not affect haemostasis in piglets. Intensive Care Med. 2007;33(9):1594-1601. doi:10.1007/s00134-007-0666-3

49. Mélot C, Vermeulen F, Maggiorini M, Gilbert E, Naeije R. Site of pulmonary vasodilation by inhaled nitric oxide in microembolic lung injury. Am J Respir Crit Care Med. 1997;156(1):75-85. doi:10.1164/ ajrccm.156.1.9603041

50. Preston IR, Sagliani KD, Roberts KE, et al. Comparison of acute hemodynamic effects of inhaled nitric oxide and inhaled epoprostenol in patients with pulmonary hypertension. Pulm Circ. 2013;3 (1):68-73. doi:10.4103/2045-8932.109916

51. Wort SJ, Evans TW. The role of the endothelium in modulating vascular control in sepsis and related conditions. Br Med Bull. 1999;55(1):30-48. doi:10.1258/0007142991902286

52. Hambraeus-Jonzon K, Bindslev L, Frostell C, Hedenstierna G. Individual lung blood flow during unilateral hypoxia: effects of inhaled nitric oxide. Eur Respir J. 1998;11(3):565-570. 


\section{Publish your work in this journal}

Drug Design, Development and Therapy is an international, peerreviewed open-access journal that spans the spectrum of drug design and development through to clinical applications. Clinical outcomes, patient safety, and programs for the development and effective, safe, and sustained use of medicines are a feature of the journal, which has also been accepted for indexing on PubMed Central. The manuscript management system is completely online and includes a very quick and fair peer-review system, which is all easy to use. Visit http://www. dovepress.com/testimonials.php to read real quotes from published authors.

Submit your manuscript here: https://www.dovepress.com/drug-design-development-and-therapy-journal 